\title{
An Elicitor from Botrytis cinerea Induces the Hypersensitive Response in Arabidopsis thaliana and Other Plants and Promotes the Gray Mold Disease
}

\author{
Eri M. Govrin, Shimon Rachmilevitch, Budhi Sagar Tiwari, Mazal Solomon, and Alex Levine
}

Department of Plant Sciences, The Hebrew University of Jerusalem, Givat-Ram Jerusalem 91904, Israel.

Accepted for publication 3 October 2005.

\begin{abstract}
Govrin, E. M., Rachmilevitch, S., Tiwari, B. S., Solomon, M., and Levine, A. 2006. An elicitor from Botrytis cinerea induces the hypersensitive response in Arabidopsis thaliana and other plants and promotes the gray mold disease. Phytopathology 96:299-307.

Botrytis cinerea is a necrotrophic fungus that infects over 200 plant species. Previous studies showed that host cells collapse in advance of the hyphae, suggesting secretion of toxins or elicitors. We have partially characterized elicitor activity from intercellular fluid extracted from Arabidopsis thaliana leaves infected with $B$. cinerea. Treatment of intact leaves or cell cultures with either intercellular fluid from infected leaves or medium from inoculated $A$. thaliana cell culture induced generation of reactive oxygen species, resulting in reduced photosynthesis, electrolyte leakage, and necrotic lesions that resembled the hypersensitive response (HR). The necrosis was inhibited by diphenyleneiodonium, a specific in-

hibitor of NADPH oxidase, and by chelating free iron, suggesting the involvement of hydroxyl radicals. The necrosis was also suppressed in $d n d l$ mutants that are compromised in HR. In contrast, increased cell death was observed in acd 2 mutants, indicating the involvement of the host defense signaling pathways. Treatment with the intercellular fluid from infected leaves also induced transcription of pathogenesis-related $(P R)$ genes, such as $P R-1, P R-5, H S R 203 J$, and of senescence-associated gene $S A G-13$. Moreover, rapid transcription of the ethylene-dependent AtEBP gene was detected, indicating induction of ethylene production. The intercellular fluid from infected A. thaliana induced cell death in other plants, in line with the lack of $B$. cinerea specificity. In summary, the intercellular fluid mimicked a range of molecular and physiological host responses that are observed during infection with a live fungus. Moreover, it accelerated the $B$. cinerea infection, suggesting that the elicitor may act as a pathogenicity factor in the progression of gray mold disease.
\end{abstract}

Botrytis cinerea is a nonspecific necrotrophic pathogen that attacks more than 200 plant species (39). B. cinerea infection is first noticeable by the appearance of small necrotic lesions at the site of inoculation. Following the primary infection, the lesions increase in size as the fungus becomes established (3). The killing of plant cells is essential for $B$. cinerea growth $(13,52)$.

During evolution, plants have developed efficient strategies to respond to attempted infections. The perception of pathogen attack that takes place by detection of microbial products, called elicitors or pathogen-associated molecular patterns, is critical for mounting a successful defense (58). Many fungi attack plants by producing general or host-specific toxins (14). Traditionally, compounds that caused rapid host cell death in the absence of detected plant defense responses were classified as toxins. In contrast, the elicitors, although also capable of triggering host cell death, are considered inducers of defense responses. Recent studies of a well-characterized toxin from Cochliobolus victoriae, victorin, which causes host cell death, revealed that it induced phytoalexin biosynthesis and other defense responses that are usually associated with elicitors (28). Moreover, inhibitors of cell death signal transduction suppressed cell death caused by victorin. Similar induction of cell death concomitant with activation of defense reactions was recently described in Arabidopsis thaliana in response to fumonisin B1 mycotoxin (45) and in tomato treated with toxins from Alternaria alternata (53). Importantly, toxin-induced cell death could be suppressed by expression of antiapoptotic

Corresponding author: A. Levine; E-mail address: AlexLevine@huji.ac.il

DOI: 10.1094/PHYTO-96-0299

(C) 2006 The American Phytopathological Society genes, such as $B c l-2$ and $B c l-x l$, indicating suicide-like cell death $(11,55)$.

Toxin production by $B$. cinerea has been suspected for many years, although its presence was never clearly demonstrated (20, 39). Gentile showed in 1951 that a thermostable, nonvolatile factor from Exochorda racemosa plants infected with $B$. cinerea could induce lesions similar to the live fungus infection (15). A phytotoxic polysaccharide factor was isolated from $B$. cinerea broth and shown to produce disease symptoms (50). More recently, a number of toxic sesquiterpene molecules, such as botrydial, have been purified from shaking cultures of $B$. cinerea $(6,40)$. However, the level of botrydial in leaves infected by different isolates did not correspond to the disease susceptibility, leading the authors to conclude that it is not a primary determinant of pathogenicity (8). This conclusion was recently corroborated by the deletion of the $B$. cinerea gene that encodes a P450 monooxygenase in the botrydial pathway, which showed only minor effect on virulence (43).

As early as 1888, Ward noticed that host cells collapsed in advance of $B$. cinerea hyphae (54). A similar conclusion was reached several years later by Smith (44). We have confirmed these observations in A. thaliana leaves, and showed that cells at a considerable distance from the growing hyphae were accumulating $\mathrm{H}_{2} \mathrm{O}_{2}$ before cell death (16). Generation of reactive oxygen species (ROS) has been documented in numerous plant-pathogen interactions (22) and shown to play a key role in the hypersensitive cell death during pathogenesis $(10,24,32)$. Moreover, $B$. cinerea disease was suppressed by pretreatment with diphenylene iodonium (DPI), an inhibitor of the plasma-membrane NADPH oxidase, indicating a critical role for host-generated ROS (16). The above observations suggested that $B$. cinerea may be secreting a factor that elicits an oxidative burst which triggers an active (programmed) cell death in the host. 
Here we describe the effects of $B$. cinerea elicitor from infected plants. We show that the cell-free intercellular fluid from $A$. thaliana leaves infected with $B$. cinerea mimicked the full range of plant responses to the fungal infection, including the oxidative burst, induction of defense gene transcription, and hypersensitive cell death.

\section{MATERIALS AND METHODS}

Materials. 2,7-Dihydrodichlorofluorescein was obtained from Molecular Probes Inc. (Eugene, OR), DAF-2 from Alexis Biochemicals (San Diego, CA), and 4',6-diamidino-2-phenyl-indole (DAPI) from Calbiochem (San Diego, CA). $\mathrm{Zn}^{2+}$ desferrioxamine was a gift from M. Chevion (Hadassah, Jerusalem, Israel), and DPI and other chemicals were obtained from Sigma Chemical (St. Louis, MO).

Plant and fungal cultures. A. thaliana plants var. Col-O were grown for 4 to 5 weeks in growth chambers at $23^{\circ} \mathrm{C}$ with $16 \mathrm{~h}$ light. Cell cultures were provided by C. J. Leaver (University of Oxford, UK). Cultures were kept at $25^{\circ} \mathrm{C}$ under constant light in Murashige and Skoog's medium supplemented with myo-inositol (100 mg/liter), thiamine $(0.4 \mathrm{mg} /$ liter $)$, naphthalene acetic acid ( $0.5 \mathrm{mg} /$ liter), kinetin ( $0.05 \mathrm{mg} / \mathrm{liter})$, and $3 \%$ sucrose. A. thaliana cultures were diluted fivefold every week and used 2 days after the transfer. B. cinerea (strain INRA) was provided by A. Mayer (The Hebrew University) and grown in constant light at $20^{\circ} \mathrm{C}$ on potato dextrose agar as previously described (17).

Preparation of intercellular fluid from infected leaves and cell-free medium from suspension-cultured cell. Spores of $B$. cinerea were collected and prepared as described in Govrin and Levine (17). The spores were diluted to the concentration of 20 spores per $\mu \mathrm{l}$, and the inoculation was done by placing a drop of $5 \mu \mathrm{l}$ in the center of the infiltrated area.

To prepare the intercellular fluid, A. thaliana plants were sprayed with $B$. cinerea spores at a concentration of $10^{5}$ spores per $\mathrm{ml}$ with a compressed air sprayer. Plants were kept for 3 days at $20^{\circ} \mathrm{C}$ in plastic boxes covered with nylon under constant light. Twenty leaves were put into $12.5 \mathrm{ml}$ of water in a $50-\mathrm{ml}$ syringe and subjected to five alternating vacuum and air pressure regiments. The material was filtered through $0.2 \mu \mathrm{m}$ and kept at $-20^{\circ} \mathrm{C}$. To estimate the endogenous concentration of the elicitor, the apoplastic water volume was determined according to Husted and Schjoerring (19), and was calculated to correspond to about $11 \%$ of the fresh leaf weight. Unless otherwise indicated, in all experiments the intercellular fluid was diluted 300-fold. For control, the apoplastic fluid was extracted from uninfected leaves in an identical manner. No necrotic symptoms were observed at any concentration of the control fluid.

The cell-free medium from A. thaliana suspension culture infected with $B$. cinerea was prepared by inoculation of $10^{4}$ spores of $B$. cinerea into a $250-\mathrm{ml}$ flask filled with $40 \mathrm{ml}$ of a 5 -dayold $A$. thaliana culture. The medium was collected after 8 days, and the cultures were washed with $40 \mathrm{ml}$ of water. The culture fluid and the water-extracted material were filtered separately through $0.2-\mu \mathrm{m}$ filters (Sartorius, Germany), and activity was tested on $A$. thaliana cells. Since the activity of the water-extracted fraction was routinely 85 to $90 \%$ of the culture medium, both fractions were pooled together. Infiltration into leaves was done with a 1-ml syringe as described in Govrin and Levine (17).

ROS measurements. ROS were assayed as described in $\mathrm{Lu}$ and Higgins (26). A minor modification was made in the method of sample preparation: leaves were removed $6 \mathrm{~h}$ after treatment, washed briefly in distilled water, and placed into glass tubes with $0.1 \mathrm{M}$ phosphate buffer, $\mathrm{pH} 8$, and 2,7-dihydrodichlorofluorescein. Aliquots were withdrawn and analyzed in a fluorometer (BioTek FL600; Bio-Tek Instruments, Winooski, VT) at $485 \mathrm{~nm}$ excitation $/ 525 \mathrm{~nm}$ emission wavelengths.
Photosynthesis measurements. Gas exchange of fully developed, attached leaves of A. thaliana was determined with a Model LCA-2 system (Analytical Development Company, Hoddesdon, England). For these measurements, different mixtures of oxygen, nitrogen, and carbon dioxide were obtained with two cascaded gas-mixing pumps (Model 2CO-18-2F; Wosthoff Co., Germany). Leaf gas exchange parameters were measured or derived by standard procedures (51). $\mathrm{CO}_{2}$ assimilation/internal leaf $\mathrm{CO}_{2}$ partial pressure $(\mathrm{A} / \mathrm{Ci})$ values were determined from gas exchange measurements made under $300 \mu \mathrm{mol} \mathrm{m} \mathrm{m}^{-2} \mathrm{~s}^{-1}$ photosynthetic photon flux.

Northern analysis. RNA preparation, blotting, and hybridization were as described in Govrin and Levine (17). The tobacco $H S R 203 J$ and the AtEBP probes were generous gifts from D. Roby (INRA, Castanet-Tolosan, France) and J. Ecker (Salk Institute, La Jolla, CA), respectively. $P R-1$ and $P R-5$ were from K. Shirazu (Salk Institute), $P D F-1.2$ from J. Dangl (University of North Carolina), and GST-1 from J. Greenberg (Boston Gen. Hosp., Boston, MA).

Fluorescent microscopy. For nuclear staining, leaves were incubated for $15 \mathrm{~min}$ in $5 \mu \mathrm{M}$ DAPI and viewed with an Olympus IX70 fluorescence microscope at 365HT25/450DF65 nm excitation/emission wavelengths. Chlorophyll autofluorescence was viewed at 535DF/OG590 nm wavelengths as described in Mazel and Levine (29). For ROS observation, leaves were incubated in $0.2 \mathrm{ml}$ of $10 \mu \mathrm{M}$ DCFH-DA for $15 \mathrm{~min}$ in the dark in phosphate buffer, $\mathrm{pH} 7.5$, and viewed at 485DF22/OG530 nm excitation/ emission wavelengths.

Conductivity assay. A total of six leaf disks, $1 \mathrm{~cm}$ in diameter, were excised from the third and fourth rosette leaves from six different plants, rinsed in water for $10 \mathrm{~min}$, and floated on the abaxial side on $3 \mathrm{ml}$ of double-distilled water for $3 \mathrm{~h}$ at room temperature. Conductivity was measured with a Consort K511 Conductometer (Scientific Instruments, Tumhout, Belgium).

\section{RESULTS}

Induction of necrosis by intercellular fluid from leaves infected with $\boldsymbol{B}$. cinerea. As a first step to examine possible production of elicitor or toxin by $B$. cinerea, we collected intercellular fluid from infected $A$. thaliana leaves and infiltrated it into leaves of naive plants. The volume of intercellular fluid was estimated by the vacuum infiltration technique, which extracts the apoplastic solution with very little cytoplasmic contamination (19). Dark, water-soaked lesions resembling B. cinerea infection began to develop within 8 to $24 \mathrm{~h}$ after infiltration of the intercellular fluid. A rapid necrosis occurred after infiltration of a twofold dilution of the intercellular fluid that spread beyond the initial infiltration area (Fig. 1A, leaf 1), and a typical necrosis, that was confined to the infiltrated area, developed within 24 to $36 \mathrm{~h}$, even after 200-fold dilution of the intercellular apoplastic concentration (Fig. 1A, leaves 2 and 3). The symptoms produced by a 300 -fold dilution of the intercellular fluid developed more slowly and were weaker, and a 5,000-fold dilution did not produce any visual symptoms even after 3 days (Fig. 1A, leaf 4 ). No symptoms were observed after infiltration of intercellular (control) fluid, which was extracted from uninfected plants (data not shown), at any concentration.

Induction of necrosis occurred at concentrations considerably below those present in infected tissue. The intercellular fluid moved with the transpiration stream when detached leaves were placed in water with the intercellular fluid (Fig. 1B). Infiltration of the medium from inoculated cell culture into A. thaliana leaves produced lesions as effectively as intercellular fluid (data not shown).

The onset of cell death was assayed by measuring ion leakage, which indicates cellular collapse (46). Cells started to die $8 \mathrm{~h}$ after infiltration of the intercellular fluid (Fig. 1C), which preceded the 
appearance of necrotic lesions by several hours. Staining of the treated leaves with DAPI revealed fluorescent nuclei in the treated area, indicating chromatin condensation which is often associated with programmed cell death (Fig. 2A) $(23,36)$. The DAPI fluorescence observed in the infiltrated area coincided with reduced chlorophyll autofluorescence and reduced photosynthetic capacity in the treated area, indicating early onset of chlorophyll damage (Fig. 2B and C). Infiltration of intercellular fluid caused a $20 \%$ decrease in photosynthesis as measured by reduced photosynthetic carbon dioxide $\left(\mathrm{CO}_{2}\right)$ uptake after $1 \mathrm{~h}$ following the infiltration and reached $50 \%$ inhibition by $4 \mathrm{~h}$. The change in $\mathrm{CO}_{2}$ concentrations per unit time is correlated with net photosynthesis (assimilation). The earliest visible necrotic symptoms appeared after more than $12 \mathrm{~h}$.
To test whether the cell death caused by the intercellular fluid from infected leaves utilized the programmed cell death signaling pathways of the host, the intercellular fluid was infiltrated into two $A$. thaliana mutants that exhibit opposing phenotypes with regard to induction of cell death during pathogenesis. We have shown previously that the dndl mutants, which do not exhibit hypersensitive cell death to avirulent strains of Pseudomonas syringae (56), were also less susceptible to infection with $B$. cinerea (16). Infiltration of the intercellular fluid from leaves infected with $B$. cinerea into the dndl leaves was symptomless (Fig. 3A), consistent with the results of live fungus infection (16). On the other hand, infiltration of the intercellular fluid into $a c d 2$ (accelerated cell death mutant) plants induced a strong and rapid necrosis com-
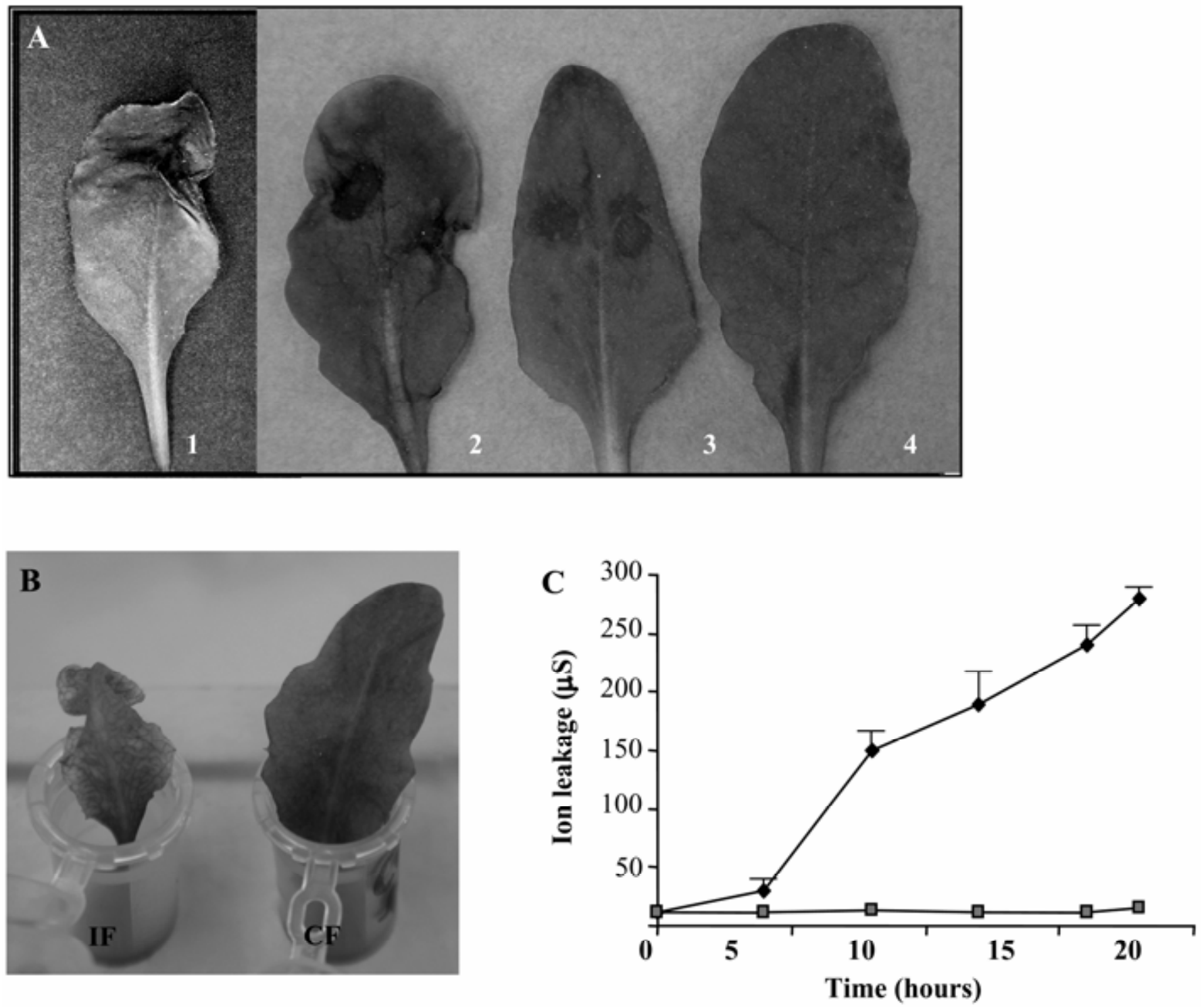

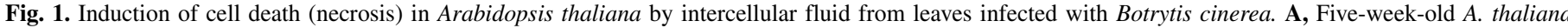

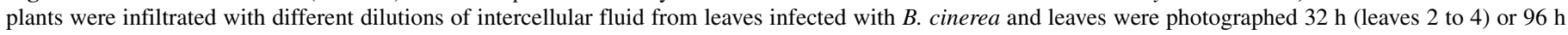

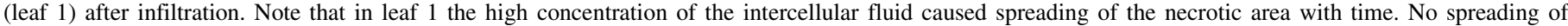

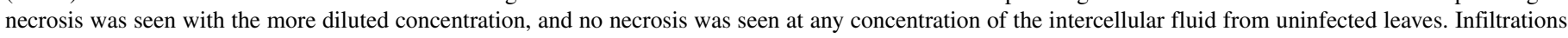

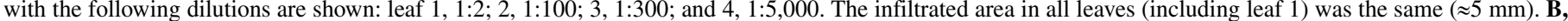

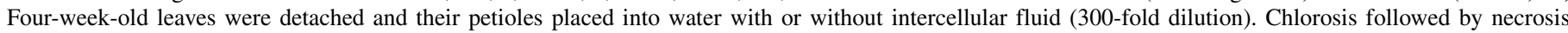

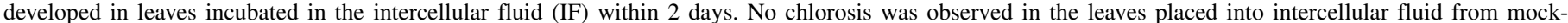

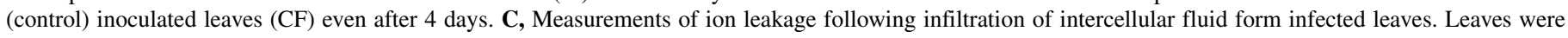

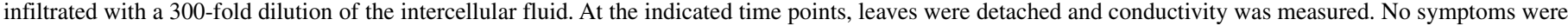
seen during the first $15 \mathrm{~h}$ after infiltration. Cell death was assayed by measuring ion leakage from leaf disks. The bars indicate standard deviation $(n=6)$. intercellular fluid from infected leaves; and $\mathbf{a}$, intercellular fluid from healthy leaves (control). 
pared with wild-type plants, where the symptoms started to appear at $48 \mathrm{~h}$.

Since $B$. cinerea is a nonspecific pathogen, it was interesting to test whether the intercellular fluid isolated from infected A. thali- ana plants induced necrosis in other species. Infiltration of the intercellular fluid from infected leaves produced necrotic lesions in bean and tobacco leaves (Fig. 3B). Similar results were obtained by infiltration of the cell-free medium from infected cell
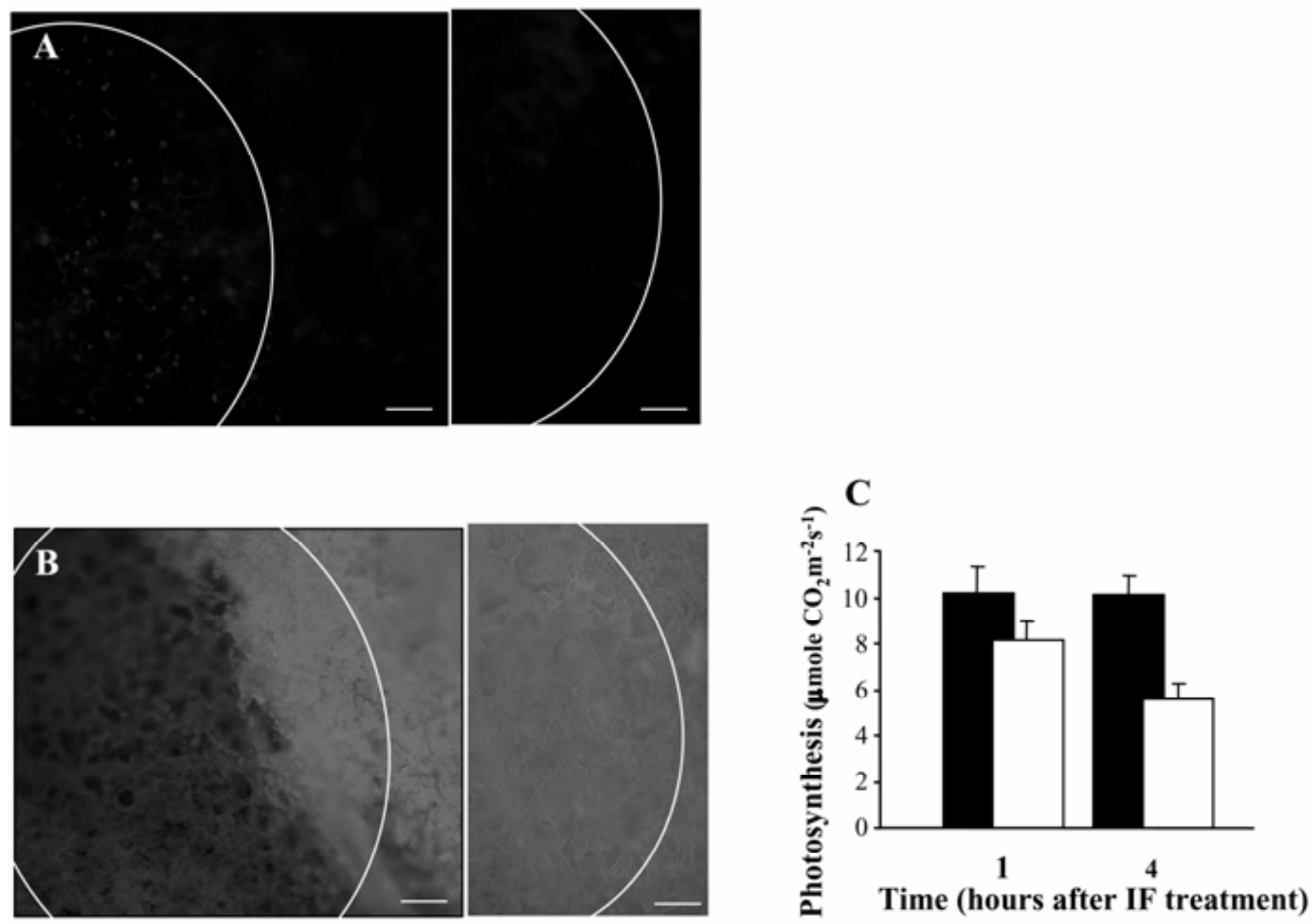

Fig. 2. Characterization of cell death caused by intercellular fluid in wild-type Arabidopsis thaliana plants. A, Condensation of chromatin in cells treated with intercellular fluid from infected leaves (left) or from control leaves (right). Intact leaves were infiltrated with intercellular fluid (300-fold dilution) and stained with 4',6-diamidino-2-phenyl-indole (DAPI) $12 \mathrm{~h}$ later. The ring delineates the infiltrated area. The picture shows fluorescence of DAPI only in the infiltrated area on the left (the center of infiltration is outside the picture frame), while no signal is seen in the healthy part of the leaf (right) or in the control treated leaves (right). B, Chlorophyll autofluorescence in the leaf treated as in $\mathbf{A}$, showing damage to the chlorophyll in the infiltrated area. The right image shows a control treated leaf. Scale bar is $100 \mu \mathrm{m}$. C, The effect of intercellular fluid on photosynthesis of A. thaliana. Leaves were infiltrated with intercellular fluid (IF) from infected leaves and the net $\mathrm{CO}_{2}$ gas exchange was measured after 1 and $4 \mathrm{~h}$. Measurements were taken under $300 \mu \mathrm{mol} \mathrm{m}^{-2} \mathrm{~s}^{-1}$ photosynthetic photon flux. Black bars, leaves treated with the intercellular fluid from infected leaves; white bars, control fluid.
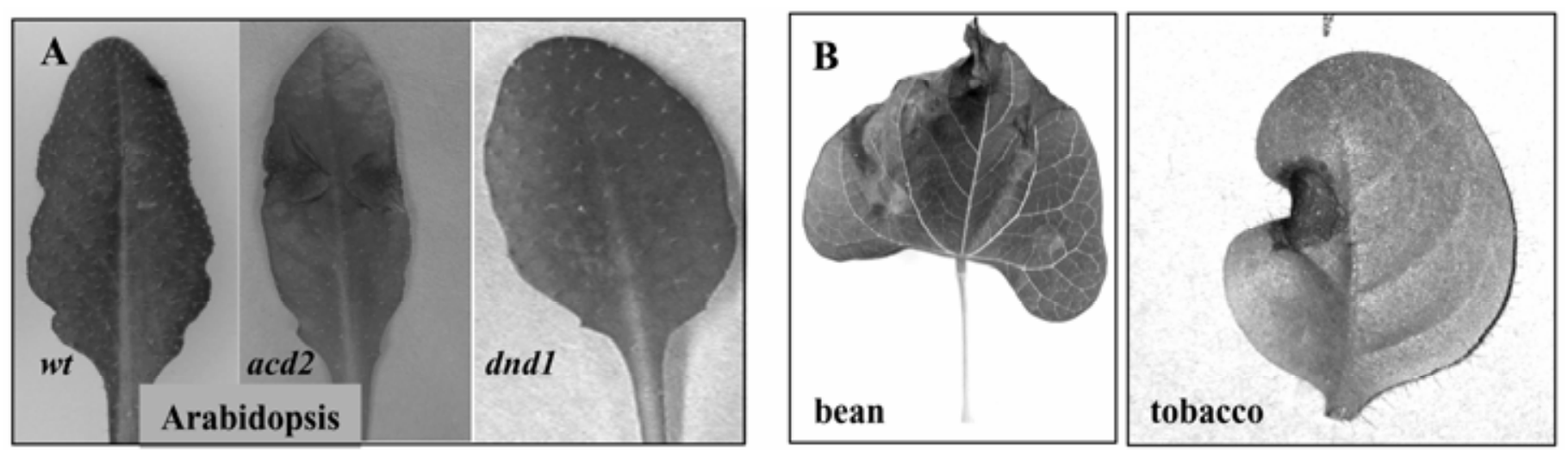

Fig. 3. Induction of cell death in mutant Arabidopsis thaliana and other plants. A, Treatment of wild type, acd2, and dnd1 mutant A. thaliana plants with intercellular fluid. Leaves were photographed $33 \mathrm{~h}$ after treatment. In the wild-type plants the symptoms appeared within $48 \mathrm{~h}$, while in the acd 2 mutants they were visible already after $24 \mathrm{~h}$, and in $d n d l$ mutants no symptoms were seen even 4 days after infiltration. B, Bean and tobacco plants were infiltrated with intercellular fluid from leaves infected with Botrytis cinerea or from leaves treated with water (control). No symptoms were seen in either plant when the leaves were infiltrated with water (data not shown). Plants were photographed $44 \mathrm{~h}$ after infiltration. 
culture from $A$. thaliana, but neither the intercellular fluid from the uninfected leaves nor cell cultures showed any visible symptoms (data not shown).

Characterization of the $B$. cinerea elicitor activity. Preliminary characterization of the necrotizing activity of the intercellular fluid from leaves infected with $B$. cinerea showed that it was caused by a small molecule that diffused through a 1-kDa cutoff dialysis membrane. Fractionation of the intercellular fluid from the infected leaves with an equal volume of ethyl acetate recovered the activity in the aqueous phase. Macromolecules were also removed by sequential precipitation with $70 \%$ and then with $95 \%$ ethanol and centrifugation. The pellet and the supernatant were lyophilized and resuspended in water and infiltrated into A. thaliana leaves. Almost $100 \%$ of the activity was retained in the supernatant. The active fraction was heat stable $\left(10 \mathrm{~min}\right.$ at $\left.95^{\circ} \mathrm{C}\right)$ and resistant to treatments with proteinase $\mathrm{K}$ and RNase $\mathrm{A}$ (data not shown). More detailed analysis will be necessary to identify the molecular structure of the active compound.

Induction of ROS by cell-free intercellular fluid from leaves infected with $B$. cinerea. One of the earliest plant responses to pathogens is the generation of ROS (22). The oxidative burst was detected within several hours of $A$. thaliana infection by $B$. cinerea $(16,52)$. It was therefore interesting to determine whether ROS production occurred in response to treatment with the cellfree intercellular fluid from leaves infected with $B$. cinerea. Increased ROS accumulation was observed in the area infiltrated with intercellular fluid from infected medium but not with the control medium (Fig. 4A, inset). Quantitative measurements confirmed the microscopy data (Fig. 4A). Infiltration of catalase abolished the fluorescence, verifying that the major ROS in the treated leaves was $\mathrm{H}_{2} \mathrm{O}_{2}$, in line with previous results from fungal infection (16).

To test the role of the ROS production in the necrosis development, the A. thaliana leaves were treated with DPI, an inhibitor of the plasma membrane NADPH oxidase $(31,33)$. The addition of DPI to the intercellular fluid from infected leaves effectively suppressed the formation of lesions, implicating the NADPH oxidase in the production of ROS and the formation of lesions (Fig. 4B). Since iron is a potent facilitator of hydroxyl radical production via the Fenton reaction (especially in the presence of $\mathrm{H}_{2} \mathrm{O}_{2}$ ), and also by virtue of hypervalent iron compounds, we tested whether free iron played a role in the development of necrosis. The free iron was chelated with a complexed desferrioxamine $(42,57)$, which was infiltrated together with the intercellular fluid. Addition of the iron chelator strongly suppressed the formation of lesions, suggesting a possible involvement of the hydroxyl radicals in necrosis (Fig. 4B).

Induction of plant defense genes by intercellular fluid. The results presented above indicate that plants perceived the presence of a soluble $B$. cinerea elicitor that activates the hypersensitive cell death pathway. To see whether the perception of intercellular fluid also triggered the signal transduction pathways that lead to the induction of defense gene transcription, we analyzed gene expression using probes from representative defense pathways that are commonly induced during pathogenesis (48). As shown in Figure 5A, the intercellular fluid from infected leaves induced defense genes from several pathways. These genes were shown earlier to be induced by the inoculation of $B$. cinerea spores, suggesting that plant cells activated the same signaling pathways in response to the intercellular fluid from infected leaves as when challenged with the live fungus (16). It is notable, that in tobacco the intercellular fluid induced the expression of the HSR203 gene, which is considered a hypersensitive response (HR)-specific gene $(37,38)$. Moreover, the HSR203 gene was induced very early, as described for the HR-specific expression of this gene in tobacco plants challenged with several incompatible pathogens. The intercellular fluid from infected leaves also induced expression of the $A t E B P$ gene, indicating a rapid increase in ethylene biosynthesis (Fig. 5B).

The effect of intercellular fluid on gray mold disease caused by $B$. cinerea. To test whether the elicitor participated in the development of $B$. cinerea disease, we treated the A. thaliana leaves with the cell-free intercellular fluid from infected leaves and then inoculated them with a relatively low number of $B$. cinerea spores (20 spores per $\mathrm{ml}$, which is fivefold less than the concentration used for rapid infection [16,17]). Substantially larger lesions were detected in plants that were infected with $B$. cinerea after treatment with the intercellular fluid from infected leaves, as opposed to infection following infiltration of intercellular fluid from mockinfected leaves (Fig. 6A). The increased lesions size was correlated to increased fungal growth, as tested by the expression of a constitutive B. cinerea-specific actin gene (Fig. 6B).
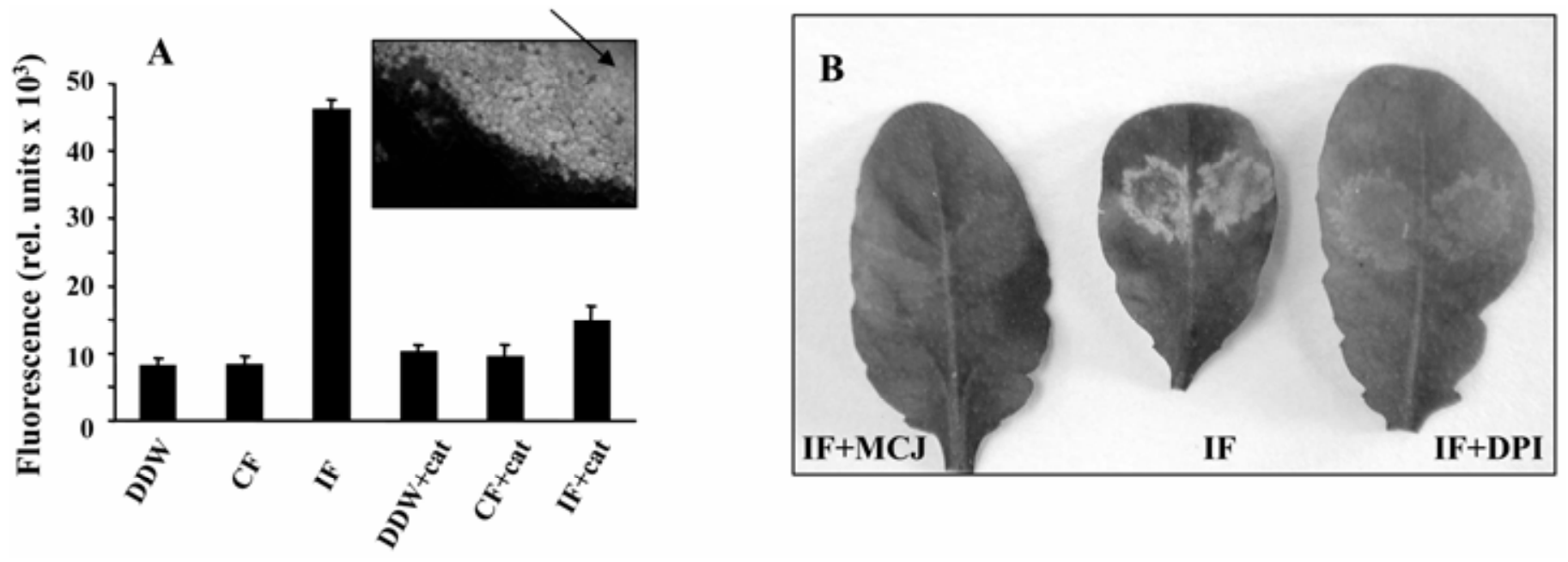

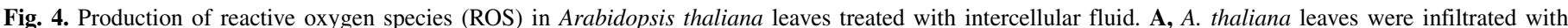

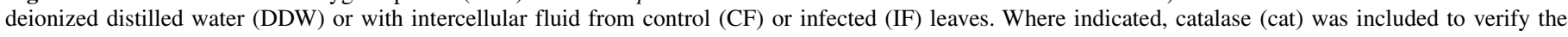

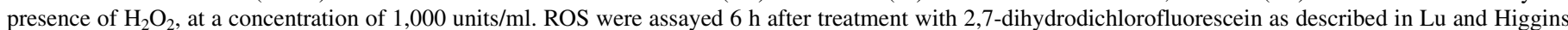

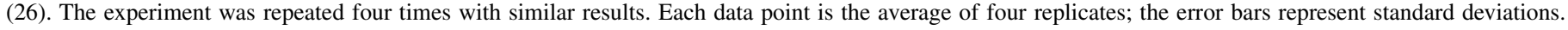

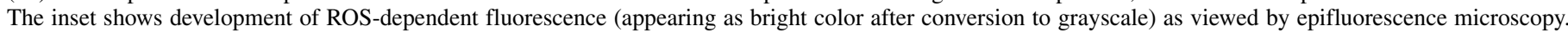

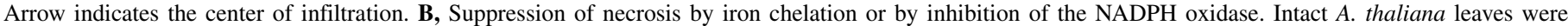

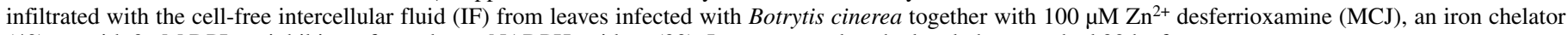
(42), or with $3 \mu \mathrm{M}$ DPI, an inhibitor of membrane NADPH oxidase (33). Leaves were detached and photographed $32 \mathrm{~h}$ after treatment. 


\section{DISCUSSION}

In this paper, we have investigated the cause of the oxidative burst and cell death in infected host tissue that occurs at a considerable distance in advance of growing $B$. cinerea hyphae $(9,16)$. The production of toxin by $B$. cinerea has been proposed some 50 years ago (15), but to date, no convincing evidence for the existence of a toxin has been shown (39). Several extracellular polygalacturonases have been isolated and shown to act as virulence factors, but mutants of $B$. cinerea in these genes were still pathogenic and exhibited identical primary infections $(39,47)$. Phytotoxic compounds of low molecular weight, such as botrydial, were previously isolated from shaking or standing liquid cultures of $B$. cinerea $(12,40)$. However, botrydial and other toxins from the $B$. cinerea cultures were never identified in plant tissues infected with isolates of $B$. cinerea. In this work, we partially characterized a potent elicitor of cell death isolated from Arabidopsis leaves inoculated with $B$. cinerea. The elicitor described here exhibited a strongly hydrophilic nature (partition into the aqueous phase in the ethyl acetate extraction) that is in contrast to botrydial, which belongs to the bicyclic sesquiterpenoid class that is highly lipophilic. The described elicitor also differs from the polysaccharide factor isolated by Vannel et al. (50) since it is soluble in ethanol.

The source of the elicitor has not been addressed in this study. Theoretically, the elicitor/toxin present in the intercellular fluid from the infected leaves could be produced by $B$. cinerea or by $A$. thaliana cells that react against $B$. cinerea. Nonetheless, the primary source of the physiological and molecular effects described here must be triggered by the fungus.
A

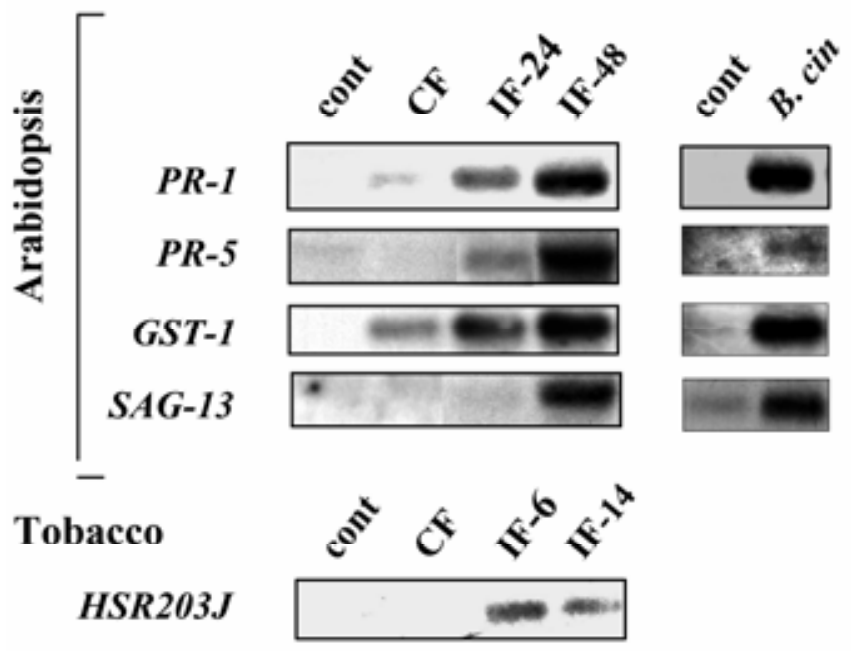

B

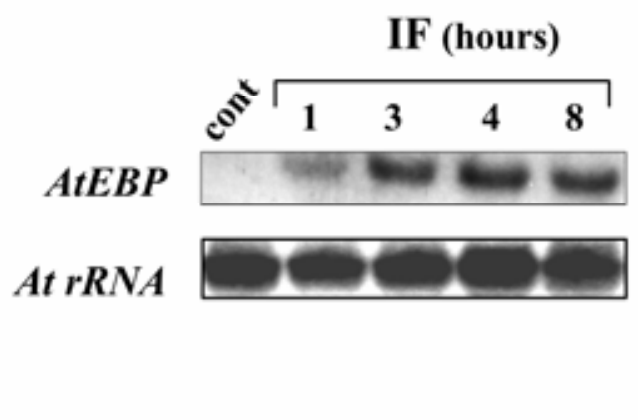

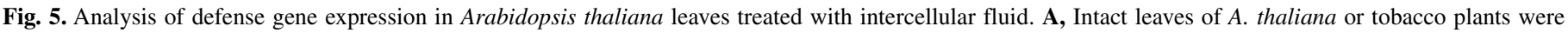

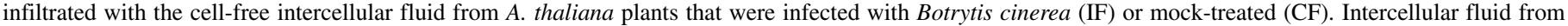

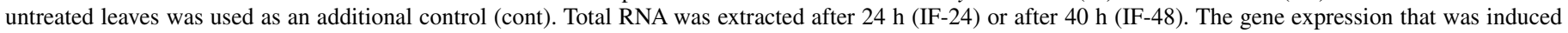

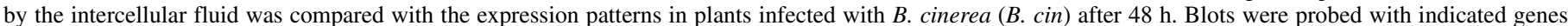

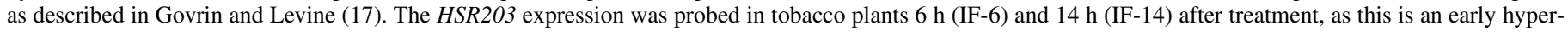

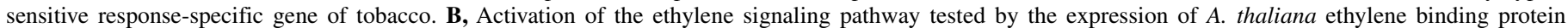

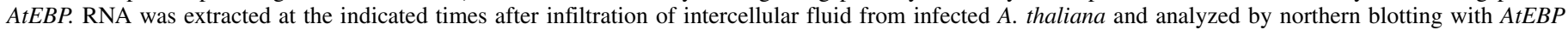
probe.
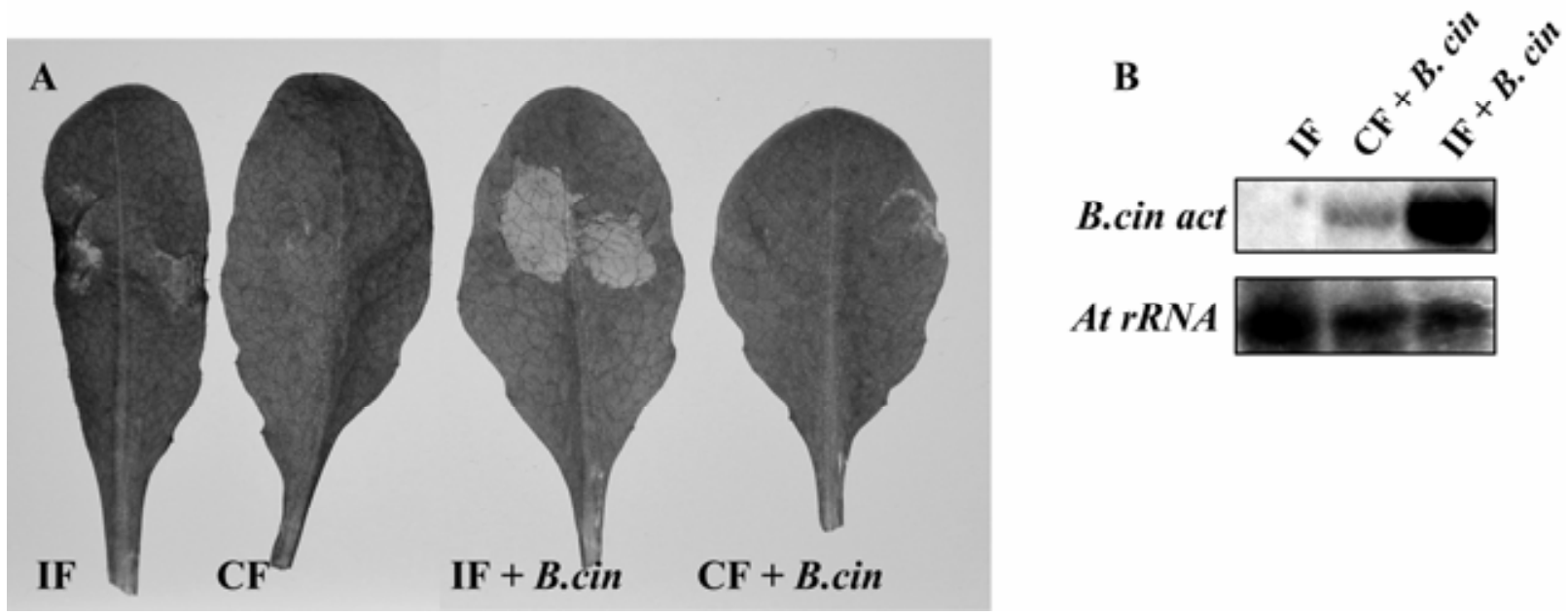

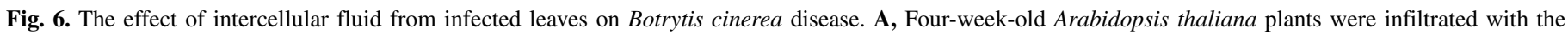

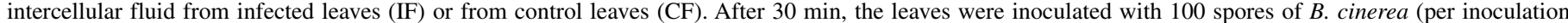

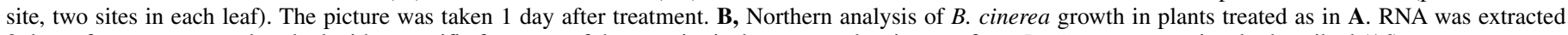
3 days after treatment and probed with a specific fragment of the constitutively expressed actin gene from $B$. cinerea, as previously described (16). 
Dependence of the $B$. cinerea elicitor activity on the host background. $B$. cinerea is a nonspecific pathogenic fungus that infects many unrelated plant species, although large variations in pathogenicity exist, especially in the infection of healthy, unwounded plants, which are naturally less susceptible to the opportunistic fungi (27). Infiltration of the intercellular fluid from infected A. thaliana tissues on healthy Arabidopsis, tobacco, and bean plants caused necrosis on all plant species tested within 36 to $48 \mathrm{~h}$, consistent with the nonspecific mode of attack of the fungus (Fig. 3B). In planta, the concentration that is required to induce necrosis is probably adjusted by the hyphal growth during the disease progression, in order to keep the toxic levels only a few cell layers ahead of the hyphal tip. Therefore, although the elicitor could move within the leaf, the lesion development was restricted (Fig. 1). Uncontrolled production and long-distance diffusion of the toxic factor would be counterproductive, since the dead tissue would desiccate prior to the fungus reaching the area to benefit from the nutrients.

$B$. cinerea is a heterokaryotic organism and consequently its genotypes are variable and susceptible to significant change. Indeed, individual isolates were shown to exhibit variable aggressiveness even on different cultivars of the same species $(9,52)$. Importantly, induction of necrosis by the intercellular fluid from infected A. thaliana plants depended on the plant's genetic background and was correlated with HR induction in these plants. Thus, the dndl mutants, which fail to mount HR to pathogens (56), produced only minor lesions, while acd2 plants, which exhibit accelerated cell death when challenged with different pathogens (18), rapidly developed a strong necrosis reaction (Fig. 3A). These results are in line with increased cell death of the acd2 mutants to the fumonisin B1 toxin (2). The results of the intercellular fluid treatments are also in agreement with the reported infection of these mutants with $B$. cinerea spores (16). Taken together, these results suggest that the $B$. cinerea elicitor activates the same cell death pathway as the live fungus and the bacterial $P$. syringae pathogens that were used to characterize those mutants.

The effect of $B$. cinerea elicitor on ROS generation. Accumulating evidence links the oxidative burst with plant cell death, including $B$. cinerea-induced hypersensitive cell death $(16,22)$. The proposed mechanism that produces ROS during the HR includes the plasma membrane NADPH oxidase and a cell wall peroxidase (5). We have previously shown that $B$. cinerea infection induced a massive $\mathrm{H}_{2} \mathrm{O}_{2}$ accumulation, which extended to a considerable distance from the growing hyphae (16). The inhibition of ROS accumulation by infiltration of catalase indicates that $\mathrm{H}_{2} \mathrm{O}_{2}$ was the main ROS that was induced by the intercellular fluid (Fig. 4A). The accumulation of $\mathrm{H}_{2} \mathrm{O}_{2}$ relatively far from the growing hyphae is contrary to $P$. syringae infection, which induces $\mathrm{H}_{2} \mathrm{O}_{2}$ only in the cells in contact with the pathogen (4). This may be the result of the diffusion of the $B$. cinerea elicitor versus the interaction with the surface bacterial elicitors, such as flagellin or lipopolysaccharide of the outer membrane of gram-negative bacteria (58). The mechanism of the $\mathrm{H}_{2} \mathrm{O}_{2}$-dependent pathogenicity by necrotrophs has been suggested to involve the formation of hydroxyl radicals $(7,21)$. The suppression of elicitor toxicity by the chelation of the free iron (Fig. 4B) is in agreement with the proposed mechanism of the $B$. cinerea-induced necrosis via the Fenton reaction.

The effect of $\boldsymbol{B}$. cinerea elicitor on photosynthesis. The infiltration of intercellular fluid from infected leaves produced rapid physiological effects at the whole plant level before appearance of necrosis, as evidenced by the inhibition of photosynthesis already $1 \mathrm{~h}$ after treatment (Fig. 2C). Light, however, was not necessary for the observed cell death since both plants and cultured cells responded similarly in the dark to the intercellular fluid from leaves (or medium from cell cultures) infected with $B$. cinerea, albeit somewhat slower (data not shown).
Light is not essential for cell death induced by victorin, although the proteolytic degradation of Rubisco during the infection of $C$. victoriae indicated indirect involvement of chloroplasts (34). The biosynthesis of callose and the induction of ROS production lead Navarre and Wolpert, the authors of that study, to conclude that victorin possessed elicitor activity (34). Responses that are typical of elicitor treatments were also described in A. thaliana plants infiltrated with fumonisin (45).

The effect of $B$. cinerea elicitor on defense gene expression. The responses of plants to pathogen attack invariably involve changes in gene expression. One of the major groups of genes that are induced during pathogenesis belong to the class of pathogenesis-related (PR) proteins $(25,35)$. Analysis of gene expression after treatment with the cell-free intercellular fluid from infected leaves revealed induction of several defense pathways. These included induction of the $P R-1$ and $P R-5$ genes, which are activated via the salicylic acid-dependent pathway (48), and the general stress inducible GST-1 gene (Fig. 5A) (41). Especially important is the induction of the HSR203J gene in tobacco, which is considered an HR-specific marker in plants $(37,38)$. Since the homologous gene has not been identified yet in A. thaliana, we assayed this gene in tobacco (Fig. 5A).

Interestingly, intercellular fluid induced the expression of a senescence-associated $S A G-13$ gene (30) (Fig. 5A). Although there is evidence of some cross-talk between the cell death pathways during HR and senescence, these processes are regulated by distinct pathways, and the senescence-like process seems to be triggered at the periphery of the HR necrotic lesion (37). This suggests that the dying cells might release a signal able to induce senescence in the neighboring cells, which would help the $B$. cinerea infection. Furthermore, $B$. cinerea infection has been associated with ethylene accumulation, which also promotes plant senescence (49). Analysis of the expression of an ethylene inducible $A t E B P$ gene (1) showed that it was induced as early as $1 \mathrm{~h}$ after infiltration of the intercellular fluid from infected leaves (Fig. 5B). The rapid induction of ethylene production suggests that the $B$. cinerea elicitor may promote the host senescence, which is advantageous to the fungus $(13,39)$.

The effect of the $B$. cinerea elicitor on the development of gray mold disease. To assess the role of elicitor production on the pathogenicity of $B$. cinerea, the intercellular fluid infiltration was followed by inoculation of a small number of $B$. cinerea spores. Leaves that were pretreated with intercellular fluid from infected leaves, but not with the control fluid, exhibited accelerated appearance of necrosis, which is characteristic of gray mold disease (Fig. 6A). The visual disease symptoms were confirmed by analyzing the accumulation of a constitutively expressed $B$. cinerea actin gene (3) (Fig. 6B). The cell death process induced by the elicitor present in the intercellular fluid resembled HR in a number of aspects, such as early induction of the oxidative burst (Fig. 4B), chromatin condensation (36), and induction of the HR marker HSR203J gene $(37,38)$.

In summary, our results show that $B$. cinerea produces an elicitor that triggers a range of host responses that are observed during infection with the live pathogen, including the hypersensitive cell death and defense gene expression. We suggest that the movement of the elicitor ahead of the growing hyphae facilitates the fungal ingress by promoting senescence and by initiating the cell death process, which is the hallmark of the gray mold disease. Purification of the elicitor and identification of its structure will enable the elucidation of its molecular mode of action.

\section{ACKNOWLEDGMENTS}

We thank A. Bent and J. Greenberg for providing the dndl and the acd 2 mutants, respectively, and D. Roby for providing the probe of HSR203J gene. This work was supported by a grant from the EU FAIR5 project PL97-3351 and by Israel Ministry of Industry and Trade. 


\section{LITERATURE CITED}

1. Alonso, J. M., Hirayama, T., Roman, G., Nourizadeh, S., and Ecker, J. R. 1999. EIN2, a bifunctional transducer of ethylene and stress responses in Arabidopsis. Science 284:2148-2152.

2. Asai, T., Stone, J. M., Heard, J. E., Kovtun, Y., Yorgey, P., Sheen, J., and Ausubel, F. M. 2000. Fumonisin B1-induced cell death in Arabidopsis protoplasts requires jasmonate-, ethylene-, and salicylate-dependent signaling pathways. Plant Cell 12:1823-1835.

3. Benito, E. P., ten Have, A., van't Klooster, J. W., and van Kan, J. A. L. 1998. Fungal and plant gene expression during synchronized infection of tomato leaves by Botrytis cinerea. Eur. J. Plant Pathol. 104:207-220.

4. Bestwick, C. S., Brown, I. R., Bennett, M. H. R., and Mansfield, J. W. 1997. Localization of hydrogen peroxide accumulation during the hypersensitive reaction of lettuce cells to Pseudomonas syringae pv. phaseolicola. Plant Cell 9:209-221.

5. Bolwell, G. P. 1999. Role of active oxygen species and NO in plant defense responses. Curr. Opin. Plant Biol. 2:287-294.

6. Collado, I. G., Hernandezgalan, R., Duranpatron, R., and Cantoral, J. M. 1995. Metabolites from a shake culture of Botrytis cinerea. Phytochemistry 38:647-650.

7. Deak, M., Horvath, G. V., Davletova, S., Torok, K., Sass, L., Vass, I., Barna, B., Kiraly, Z., and Dudits, D. 1999. Plants ectopically expressing the iron-binding protein, ferritin, are tolerant to oxidative damage and pathogens. Nat. Biotechnol. 17:192-196.

8. Deighton, N., Muckenschnabel, I., Colmenares, A. J., Collado, I. G., and Williamson, B. 2001. Botrydial is produced in plant tissues infected by Botrytis cinerea. Phytochemistry 57:689-692.

9. Derckel, J. P., Baillieul, F., Manteau, S., Audran, J. C., Haye, B., Lambert, B., and Legendre, L. 1999. Differential induction of grapevine defenses by two strains of Botrytis cinerea. Phytopathology 89:197-203.

10. Desikan, R., Reynolds, A., Hancock, J. T., and Neill, S. J. 1998. Harpin and hydrogen peroxide both initiate programmed cell death but have differential effects on defense gene expression in Arabidopsis suspension cultures. Biochem. J. 330:115-120.

11. Dickman, M. B., Park, Y. K., Oltersdorf, T., Li, W., Clemente, T., and French, R. 2001. Abrogation of disease development in plants expressing animal antiapoptotic genes. Proc. Natl. Acad. Sci. USA 98:6957-6962.

12. Duran-Patron, R., Hernandez-Galan, R., Rebordinos, L. G., Cantoral, J. M., and Collado, I. G. 1999. Structure-activity relationships of new phytotoxic metabolites with the botryane skeleton from Botrytis cinerea. Tetrahedron 55:2389-2400.

13. Elad, Y. 1997. Responses of plants to infection by Botrytis cinerea and novel means involved in reducing their susceptibility to infection. Biol. Rev. Cambridge Philosophical Soc. 72:381-422.

14. Gabriel, D. W. 1999. Why do pathogens carry avirulence genes? Physiol. Mol. Plant Pathol. 55:205-214.

15. Gentile, A. C. 1951. A study of the toxin produced by the isolate of Botrytis cinerea from Exochorda. Physiol. Plant 4:370-386.

16. Govrin, E. M., and Levine, A. 2000. The hypersensitive response facilitates plant infection by the necrotrophic pathogen Botrytis cinerea. Curr. Biol. 10:751-757.

17. Govrin, E. M., and Levine, A. 2002. Infection of Arabidopsis with a necrotrophic pathogen, Botrytis cinerea, elicits various defense responses but does not induce systemic acquired resistance (SAR). Plant Mol. Biol. 48:267-276.

18. Greenberg, J. T., Guo, A., Klessig, D. F., and Ausubel, F. M. 1994. Programmed cell death in plants: A pathogen-triggered response activated coordinately with multiple defense functions. Cell 77:551-563.

19. Husted, S., and Schjoerring, J. K. 1995. Apoplastic PH and ammonium concentration in leaves of Brassica napus L. Plant Physiol. 109:14531460.

20. Isaac, S. 1992. Fungal-Plant Interactions. Chapman \& Hall, Edinburgh.

21. Jennings, D. B., Ehrenshaft, M., Pharr, D. M., and Williamson, J. D. 1998. Roles for mannitol and mannitol dehydrogenase in active oxygen-mediated plant defense. Proc. Natl. Acad. Sci. USA 95:1512915133.

22. Lamb, C., and Dixon, R. A. 1997. The oxidative burst in plant disease resistance. Annu. Rev. Plant Physiol. Plant Mol. Biol. 48:251-275.

23. Levine, A., Pennell, R., Alvarez, M., Palmer, R., and Lamb, C. J. 1996. Calcium-mediated apoptosis in a plant hypersensitive disease resistance response. Curr. Biol. 6:427-437.

24. Levine, A., Tenhaken, R., Dixon, R., and Lamb, C. $1994 . \mathrm{H}_{2} \mathrm{O}_{2}$ from the oxidative burst orchestrates the plant hypersensitive disease resistance response. Cell 79:583-593.

25. Linthorst, H. J. M. 1991. Pathogenesis-related proteins of plants. Crit. Rev. Plant Sci. 10:123-150.

26. Lu, H., and Higgins, V. J. 1998. Measurement of active oxygen species generated in planta in response to elicitor AVR9 of Cladosporium fulvum. Physiol. Mol. Plant Pathol. 52:35-51.
27. Mansfield, J. W. 1980. Mechanisms of resistance to Botrytis. Pages 181218 in: The Biology of Botrytis. J. R. Coley-Smith, K. Verhoeff, and W. R. Jarvis, eds. Academic Press, London.

28. Mayama, S., Tani, T., Ueno, T., Midland, S. L., Simms, J. J., and Keen, N. T. 1986. The purification of victorin and its phytoalexin elicitor activity in oat leaves. Physiol. Mol. Plant Pathol. 29:1-18.

29. Mazel, A., and Levine, A. 2001. Induction of cell death in Arabidopsis by superoxide in combination with salicylic acid or with protein synthesis inhibitors. Free Radic. Biol. Medic. 30:98-106.

30. Miller, J. D., Arteca, R. N., and Pell, E. J. 1999. Senescence-associated gene expression during ozone-induced leaf senescence in Arabidopsis. Plant Physiol. 120:1015-1023.

31. Mithoefer, A., Daxberger, A., Fromhold-Treu, D., and Ebel, J. 1997. Involvement of an $\mathrm{NAD}(\mathrm{P}) \mathrm{H}$ oxidase in the elicitor-inducible oxidative burst of soybean. Phytochemistry 45:1101-1107.

32. Mittler, R., Herr, E. H., Orvar, B. L., van Camp, W., Willekens, H., Inze, D., and Ellis, B. E. 1999. Transgenic tobacco plants with reduced capability to detoxify reactive oxygen intermediates are hyperresponsive to pathogen infection. Proc. Natl. Acad. Sci. USA 96:14165-14170.

33. Murphy, T. M., and Auh, C. K. 1996. The superoxide synthases of plasma membrane preparations from cultured rose cells. Plant Physiol. 110:621629.

34. Navarre, D. A., and Wolpert, T. J. 1999. Victorin induction of an apoptotic/senescence-like response in oats. Plant Cell 11:237-249.

35. Ohashi, Y., and Ohshima, M. 1992. Stress-induced expression of genes for pathogenesis-related proteins in plants. Plant Cell Physiol. 33:819-826.

36. Pennell, R. I., and Lamb, C. 1997. Programmed cell death in plants. Plant Cell 9:1157-1168.

37. Pontier, D., Gan, S. S., Amasino, R. M., Roby, D., and Lam, E. 1999. Markers for hypersensitive response and senescence show distinct patterns of expression. Plant Mol. Biol. 39:1243-1255.

38. Pontier, D., Godiard, L., Marco, Y., and Roby, D. 1994. Hsr203J, a tobacco gene whose activation is rapid, highly localized and specific for incompatible plant/pathogen interactions. Plant J. 5:507-521.

39. Prins, T. W., Tudzynski, P., von Tiedemann, A., Tudzynski, B., Have, A., Hansen, M. E., Tenberge, K., and van Kan, J. A. L. 2000. Infection strategies of Botrytis cinerea and related necrotrophic pathogens. Pages 33-64 in: Fungal Pathology. J. Kronstad, ed. Kluwer Academic Publishers, Dordrecht, The Netherlands.

40. Rebordinos, L., Cantoral, J. M., Prieto, M. V., Hanson, J. R., and Collado, I. G. 1996. The phytotoxic activity of some metabolites of Botrytis cinerea. Phytochemistry 42:383-387.

41. Reuber, T. L., Plotnikova, J. M., Dewdney, J., Rogers, E. E., Wood, W., and Ausubel, F. M. 1998. Correlation of defense gene induction defects with powdery mildew susceptibility in Arabidopsis enhanced disease susceptibility mutants. Plant J. 16:473-485.

42. Schubert, D., and Chevion, M. 1995. The role of iron in beta-amyloid toxicity. Biochem. Biophys. Res. Commun. 216:702-707.

43. Siewers, V., Viaud, M., Jimenez-Teja, D., Collado, I. G., Gronover, C. S., Pradier, J. M., Tudzynski, B., and Tudzynski, P. 2005. Functional analysis of the cytochrome P450 monooxygenase gene bcbot1 of Botrytis cinerea indicates that botrydial is a strain-specific virulence factor. Mol. PlantMicrobe Interact. 18:602-612.

44. Smith, R. E. 1902. The parasitism of Botrytis cinerea. Bot. Gaz. 33:421436.

45. Stone, J. M., Heard, J. E., Asai, T., and Ausubel, F. M. 2000. Simulation of fungal-mediated cell death by fumonisin B1 and selection of fumonisin B1-resistant (fbr) Arabidopsis mutants. Plant Cell 12:1811-1822.

46. Tamagnone, L., Merida, A., Stacey, N., Plaskitt, K., Parr, A., Chang, C. F., Lynn, D., Dow, J. M., Roberts, K., and Martin, C. 1998. Inhibition of phenolic acid metabolism results in precocious cell death and altered cell morphology in leaves of transgenic tobacco plants. Plant Cell 10:18011816.

47. Ten Have, A., Mulder, W., Visser, J., and van Kan, J. A. L. 1998. The endopolygalacturonase gene Bcpg1 is required for full virulence of Botrytis cinerea. Mol. Plant-Microbe Interact. 11:1009-1016.

48. Thomma, B., Eggermont, K., Penninckx, I., Mauch-Mani, B., Vogelsang, R., Cammue, B. P. A., and Broekaert, W. F. 1998. Separate jasmonatedependent and salicylate-dependent defense-response pathways in Arabidopsis are essential for resistance to distinct microbial pathogens. Proc. Natl. Acad. Sci. USA 95:15107-15111.

49. Thomma, B., Eggermont, K., Tierens, K., and Broekaert, W. F. 1999. Requirement of functional ethylene-insensitive 2 gene for efficient resistance of Arabidopsis to infection by Botrytis cinerea. Plant Physiol. 121:10931101.

50. Vannel, D., Barbier, M., and Bessis, R. 1991. Study of culture filtrate toxicity of Botrytis cinerea observed on grapevine vitroplants. 2. Effect of various fractions isolated from the crude culture filtrate. Vitis 30: 213-218.

51. Von Caemmerer, S., and Farquhar, G. D. 1981. Some relationships be- 
tween the biochemistry of photosynthesis and the gas exchange of leaves kidney beans. Planta 153:376-387.

52. von Tiedemann, A. V. 1997. Evidence for a primary role of active oxygen species in induction of host cell death during infection of bean leaves with Botrytis cinerea. Physiol. Mol. Plant Pathol. 50:151-166.

53. Wang, H., Li, J., Bostock, R. M., and Gilchrist, D. G. 1996. Apoptosis: A functional paradigm for programmed plant cell death induced by a hostselective phytotoxin and invoked during development. Plant Cell 8:375391.

54. Ward, H. M. 1888. About: Collapse of host cells prior to Botrytis cinerea penetration. Ann. Bot. 2:319-382.
55. Wolpert, T. J., Dunkle, L. D., and Ciuffetti, L. M. 2002. Host-selective toxins and avirulence determinants: What's in a name? Annu. Rev. Phytopathol. 40:251-285.

56. Yu, I. C., Parker, J., and Bent, A. F. 1998. Gene-for-gene disease resistance without the hypersensitive response in Arabidopsis dndl mutant. Proc. Natl. Acad. Sci. USA 95:7819-7824.

57. Zer, H., Peleg, I., and Chevion, M. 1994. The protective effect of desferrioxamine on paraquat-treated pea (Pisum sativum). Physiol. Plant 92:437442.

58. Zipfel, C., and Felix, G. 2005. Plants and animals: A different taste for microbes? Curr. Opin. Plant Biol. 8:353-360. 